\title{
An automatic incision device for obtaining blood samples from the heels of preterm infants causes less damage than a conventional manual lancet
}

\author{
H Vertanen, V Fellman, M Brommels, L Viinikka
}

\begin{abstract}
Objectives-To evaluate in a randomised blind study the effect on puncture site lesions of two different incision devices used to obtain blood samples from preterm infants by repeated heel sticks.

Setting-The neonatal intensive care unit at the Hospital for Children and Adolescents and Laboratory, Helsinki University Central Hospital.

Patients-A total of 100 preterm infants (birth weight below $2500 \mathrm{~g}$ ) not previously subjected to heel stick sampling.

Interventions-The infants were randomly allocated to blood sampling from the heel with either a conventional manual lancet or an automatic incision device. The same type of lancet was used for any given baby throughout the study (2-21 days).

Main outcome measures-The damage caused by sampling was evaluated using four criteria: bruising of the heel, inflammation of the heel, bruising of either the ankle or the leg, and skin healing at the puncture site. The evaluation was based on photographs presenting typical categories of each outcome.

Results-To obtain a sufficient volume of blood, on average 2.6 times more punctures were needed when the conventional manual lancet was used than when the automatic incision device was used. Heels punctured with the lancet had more bruising $(100 \% v 84 \%)$ and more signs of inflammation $(79 \% v 53 \%)$, and there was more bruising of the ankle or leg $(92 \% v$ $53 \%)$ than when the automatic incision device was used. Skin healed equally rapidly in the two groups.

Conclusion-The use of an automatic incision device for collecting repeated skin puncture samples from preterm infants is less traumatic than the use of a conventional manual lancet.

(Arch Dis Child Fetal Neonatal Ed 2001;84:F53-F55)
\end{abstract}

Keywords: newborn; blood sampling; skin puncture; puncture site healing; heel

Blood samples from infants can be obtained from either an indwelling catheter or a heel puncture. ${ }^{1-5}$ The heel stick procedure is commonly used, although it is both painful and stressful for the newborn. ${ }^{6-11}$ As a result of frequent sampling, the heels of the preterm infant may become damaged or inflamed. ${ }^{12-15}$ There are few studies on the complications of blood sample collection. Only three reports have documented the bruising and healing of the heel after a single blood sampling occasion. ${ }^{16-18}$ The effects of multiple heel sticks has not been reported. Recently, several new blood sampling devices have been introduced. The purpose of this work was to develop a rating scale for evaluation of the damage caused by repeated heel stick sampling and to perform a randomised trial comparing blindly the damage to the heel of the preterm infant after repeated heel stick sampling using an automatic incision device or a conventional manual lancet.

Patients and design of the study

The study protocol was approved by the ethics committee of the Hospital for Children and Adolescents, Helsinki University Central Hospital, Finland. Written informed consent was obtained from the parents before the infant's enrollment. All parents contacted consented to the study.

All preterm infants with a birth weight of less than $2500 \mathrm{~g}$, who were admitted to the neonatal intensive care unit without any previous heel stick sampling, were eligible for the study. In total, 100 infants were enrolled. They were randomised at admission into two groups. In one group, a conventional manual lancet (Microlance; Becton-Dickinson, Meylan Cedex, France) was used for blood collection. In the other group, an automatic incision device (Tenderfoot preemie; International Technidyne Corporation, Edison, New Jersey, USA) was used. The Microlance is a conventional manual lancet with a blade length of 2.4 $\mathrm{mm}$, and its puncture wound is not standardised. The Tenderfoot preemie is a fully automatic incision device producing a standardised wound with a depth of $0.85 \mathrm{~mm}$ and a length of $1.75 \mathrm{~mm}$. The same type of lancet was used for any given baby throughout the duration of the study (2-21 days). The principles of the Scandinavian recommendation for the collection of skin puncture blood samples were followed. ${ }^{19}$ The heel was warmed before sampling using a disposable plastic bag containing water at a temperature of $+39^{\circ} \mathrm{C}$. Samples were obtained from the outer regions of the heel. The study period was limited to 21 days, because discharge from the unit often occurs at this time.

Pilot study

A pilot study lasting two months preceded the randomised trial. Its main purpose was to develop a photograph based rating scale of the 
Table 1 Clinical background of the infants, number of sampling procedures, and number of punctures

\begin{tabular}{lllll}
\hline & Microlance $(n=38)$ & $\begin{array}{l}\text { Tenderfoot preemie } \\
(n=32)\end{array}$ & $t$ Value & $p$ Value \\
\hline Gestational age (weeks) & $29(24-35)$ & $29(24-33)$ & -0.17 & 0.87 \\
Birth weight (g) & $1209(580-2070)$ & $1195(585-2170)$ & 0.13 & 0.89 \\
Blood sampling/infant (n) & $24(4-50)$ & $18(3-41)$ & 1.74 & 0.09 \\
Skin punctures/infant (n) & $57(11-142)$ & $22(3-47)$ & 5.57 & $<0.001$ \\
\hline
\end{tabular}

Values are expressed as mean (range).

Table 2 Recovery of the heels after repeated heel sticks

\begin{tabular}{lllll}
\hline & Microlance & Tenderfoot preemie & $\chi^{2}$ test & p Value \\
\hline $\begin{array}{l}\text { Bruising of the heel } \\
\text { No } \\
\text { Yes }\end{array}$ & $0(0)$ & $5(16)$ & 6.39 & $<0.01$ \\
Inflammation of the heel & $38(100)$ & $27(84)$ & & \\
$\quad$ No & $8(21)$ & $15(47)$ & 5.25 & $<0.05$ \\
$\quad$ Yes & $30(79)$ & $17(53)$ & & \\
Bruising of the ankle or leg & $3(8)$ & $15(47)$ & 13.82 & $<0.001$ \\
$\quad$ No & $35(92)$ & $17(53)$ & & \\
$\quad$ Yes & $10(26)$ & $12(38)$ & 1.01 & 0.32 \\
$\quad \begin{array}{l}\text { Skin healing of the puncture site } \\
\text { Poor }\end{array}$ & $28(74)$ & $20(62)$ & & \\
\hline
\end{tabular}

Values are numbers with percentages in parentheses.

Table 3 Complication-free consecutive sampling times

\begin{tabular}{llll}
\hline & Microlance & Tenderfoot preemie & p Value \\
\hline Bruising of the heel & $0.15(0.02-0.80)$ & $0.28(0.08-1.00)$ & $<0.001$ \\
Inflammation of the heel & $0.41(0.02-1.00)$ & $0.89(0.08-1.00)$ & $<0.001$ \\
Bruising of the ankle or leg & $0.26(0.02-1.00)$ & $0.83(0.08-1.00)$ & $<0.001$ \\
Skin healing of the puncture site & $0.38(0.02-1.00)$ & $0.64(0.08-1.00)$ & 0.046 \\
\hline
\end{tabular}

The value given is calculated by dividing the number of sampling occasions preceding the occurrence of complications by the total number of sampling occasions for that individual. Thus if the total number of sampling occasions was 20 and bruising occurred after the 12 th time, the value is $11 / 20=0.55$. Values are expressed as median (range).

observations on heels, ankles, and legs of ten infants, to practise the use of that scale, and to evaluate it. The interobserver reliability was tested by seven nurses evaluating the heels of ten infants. The left and right heels were evaluated separately. The second purpose of the pilot study was to practise and standardise the blood sampling procedure. During the pilot study, the participating laboratory technologists $(n=29)$, who were skilled in using a conventional manual lancet, were taught to use the automatic incision device with a standardised procedure. ${ }^{19}$

\section{Outcome measures}

The puncture site lesions were used as outcome measures. Nurses who worked on the neonatal intensive care unit $(n=61)$ evaluated the condition of the heels every morning before the daily sample collection; they were unaware of the device used for the heel stick. The left and right heel were evaluated separately using the standardised set of photographs presenting typical findings for each category and each outcome. Initially, three categories were defined for the bruising and inflammation of the heel and the healing of the puncture site, and two categories for the bruising of the ankle or leg. The categories were allocated scores as follows: (a) presence of bruising on the heel $(1$, no bruising; 2, small bruises at the puncture site; 3 , large areas of bruising); (b) inflammation of the heel (1, no inflammation; 2, slight red inflammation; 3, red, warm, inflamed); (c) bruising on the ankle or leg (yes or no); (d) skin healing of the puncture site $(1$, no puncture wounds; 2 , wounds present but well healed; 3 , puncture wounds poorly healed, and scars or seeping blood present).

Each of the four aspects were evaluated and rated separately. However, because of difficulties with assessing the difference between categories 2 and 3 in bruising and inflammation of the heel and categories 1 and 2 in assessing skin healing, these outcomes were regrouped into two classes: "fair" and "poor". Category 1 when bruising and inflammation of the heel were being assessed was defined as "no" and categories 2 and 3 as "yes". Categories 1 and 2 for assessment of skin healing of the puncture site were defined as "fair" and category 3 as "poor". The infant was classified in the category "yes" or "poor" even if a single such assessment appeared in the series of observations.

Statistical analysis was performed using the SAS v6.12 program (SAS Institute Inc, Cary, North Carolina, USA) and SPSS v8.0 program (SPSS Inc, Chicago, Illinois, USA). Differences between the groups were analysed with Student's $t$ test (continuous variables) and the $\chi^{2}$ test or Fisher test (categorical variables).

\section{Results}

RELIABILITY OF THE METHOD

Six nurses evaluated 20 heels, and one nurse 14 heels, totalling 134 evaluations. A similar classification was made in $85.1 \%$ (114 v 134) of the evaluations of bruising of the heel. The figure was $79.9 \%$ (107 v 134) for inflammation of the heel, $90.3 \%$ (121 v 134) for bruising of the ankle or leg, and 94\% (126 v 134) for evaluation of skin healing of the puncture wounds.

EFFECT OF USING THE SAMPLING DEVICE

Of the 100 infants enrolled, eight had only intravenous blood sampling, and 11 were discharged during the first or second day after sampling, and thus no evaluations were made; another eight newborns were discharged because of the evaluation made only once after one heel stick sampling. For three infants, the study period was discontinued before discharge because the incision device was accidentally changed and therefore appropriate information could not be obtained. Thus the final study population consisted of 70 infants, of whom 38 belonged to the group sampled with the manual lancet ( $M$ group) and 32 to the group sampled with the automatic device (TP group). Birth weight, gestational age, and blood sampling did not differ significantly between the groups (table 1). A total of 675 heel evaluations were performed, 382 (mean 10 (range 1-20) per infant) in the $M$ group and 288 (mean 9 (range 1-18) per infant) in the TP group. The $M$ group had on average 2.6 times more punctures than the TP group (table 1).

The $M$ group had more heel bruising than the TP group, more signs of inflammation, and more bruising of the ankle and leg. However, the healing of the puncture sites did not 
depend on the type of incision device (table 2). For all parameters evaluated, the number of consecutive complication-free samplings was greater in the TP group (table 3 ).

\section{Discussion}

Neonatal intensive care requires laboratory tests and repeated blood sampling. There are many risks associated with skin punctures, such as bruising of the puncture site and inflammation. The type of sampling device may have a major effect on these risks. ${ }^{13-15} 20$

In previous studies, ${ }^{16-18}$ only the effect of a single puncture has been studied. In routine clinical work, repeated skin punture samples are needed, and therefore this study set out to investigate the effects of repeated skin punctures. The study population consisted of preterm infants, because several laboratory tests are needed for such patients and the risk of complications associated with repeated skin punctures is considerable because of their immaturity. ${ }^{12-14} 21-22$

In a previous study, ${ }^{23}$ the quality of the blood sample depended on the inflammation of the puncture site. We broadened this perspective to observe also the presence of bruising on the limb and healing of the puncture site. The evaluation aimed to be as blind and standardised as possible. As the two types of incision device create different types of wound, a fully blinded study was not possible. Although the evaluation of the puncture sites may include some subjective effect, acceptable reliability was achieved, as shown by the high interobserver agreement rate measured after a training scheme before the project.

The use of the automatic incision device appeared to be less traumatic than use of a manual lancet, as the former caused less bruising on the heel, ankle, and leg and less heel inflammation as well as significantly more complication-free sampling times in all aspects evaluated. Only the healing of the skin puncture wounds was similar in the two groups. Previous studies ${ }^{16}{ }^{17}$ showed that, even when only single blood collections were compared, the puncture wounds produced by an automatic incision device healed more efficiently than those made with a conventional manual lancet. The reason was assumed to be the depth of the puncture. The automatic device makes a wound less than $1.0 \mathrm{~mm}$ deep, whereas a lancet makes a $2.4 \mathrm{~mm}$ deep cut. Other possible reasons for the automatic incision device being more gentle may be that fewer punctures are needed to obtain sufficient blood, the total time of specimen collection and limb fixation are shorter, and the samples are obtained without squeezing the heel. ${ }^{16-18}$ Preterm infants react sensitively to handling, so even prewarming of the heel and squeezing it may cause appreciable stress and pain. ${ }^{78}$
In conclusion, an automatic incision device, which makes longer but less deep wounds than a conventional manual lancet, causes less damage to the heels of premature infants when used for repeated blood sampling.

We thank the staff of the neonatal intensive care unit and laboratory for their skilled cooperation throughout this study, and the parents of the infants who participated. We also thank Hanna Oksanen, $\mathrm{PhD}$, for statistical advice (Clinical Research Institute, Helsinki University Central Hospital). This study was supported by grants from the International Technidyne Corporation, Edison, New Jersey, USA, the Clinical Research Institute, Helsinki University Central Hospital, the Foundation for Promoting Laboratory Medicine, and Helsinki University Central Hospital.

1 Nexø E, Christensen NC, Olesen H. Volume of blood removed for analytical purposes during hospitalization of low-birthweight infants. Clin Chem 1981;27:759-61.

2 Obladen M, Sachsenweger M, Stahnke M. Blood sampling Obladen $M$, Sachsenweger $M$, Stahnke $M$. Blood sampling
in very low birth weight infants receiving different levels of intensive care. Pediatrics 1988;147:399-404.

3 Meites S, Glassco KM. Studies on the quality of specimens obtained by skin-puncture of children. 2. An analysis of blood-collecting practices in a pediatric hospital. Clin Chem 1985;31:1669-72.

4 Meites S. Skin-puncture and blood-collecting technique for infants: update and problems. Clin Chem 1988;34:1890-4.

5 Ringer SA, Richardson DK, Sacher RA, Kezler M, Churchill WH. Variations in transfusion practice in neonatal intensive care. Pediatrics 1998;101:194-200.

6 Owens ME, Todt EH. Pain in infancy: neonatal reaction to a heel lance. Pain 1984;20:77-86.

7 McIntosh N, Van Veen L, Brameyer H. The pain of heel prick and its measurement in preterm infants. Pain 1993;52:71-4.

8 Johnston CC, Stevens BJ, Yang F, Horton L. Differential response to pain by very premature neonates. Pain 1995;61:471-9.

9 Johnston CC, Stevens BJ. Experience in a neonatal intensive care unit affects pain response. Pediatrics 1996;98:925-30.

10 Larsson BA, Tannfeldt G, Lagercrantz H, Olsson GL. Alleviation of the pain of venepuncture in neonates. Acta Paeviation of the pain of
diatr 1998;87:774-9.

11 Larsson BA, Tannfeldt G, Lagercrantz H, Olsson GL. Venipuncture is more effective and less painful than heel lancing for blood tests in neonates. Pediatrics 1998;101:882-6.

12 Lilien LD, Harris VJ, Ramamurthy RS, Pildes RS. Neonatal osteomyelitis of the calcaneus: complication of heel puncture. F Pediatr 1976;88:478-80

13 Blumenfeld TA, Turi GK, Blank WA. Recommended site and depth of newborn heel skin puncture based on anatomical measurements and histopathology. Lancet 1979;i:230-3.

14 Sell EJ, Hansen RC, Struck-Pierce S. Calcified nodules on the heel: a complication of neonatal intensive care. $\mathcal{F}$ Pediatr 1980;96:473-5.

15 Reiner CB, Meites S, Hayes JR. Optimal sites and dephts for skin puncture of infants and children as assessed from skin puncture of infants and children as assessed from

16 Burns ER. Development and evaluation of a new instrument for safe heelstick sampling of neonates. Lab Med 1989;20:481-3

17 Blain-Lewis N. Comparative studies of bruising and healing after heelstick. Neonatal Intensive Care 1992 Sep/Oct:1821.

18 Paes B, Janes M, Vegh P, LaDuca F, Andrew M. A comparative study of heel-stick devices for infant blood collection. American fournal of Diseases in Children 1993;147:346-8.

19 Alström T, Dahl M, Gräsbeck R, et al. Recommendation for collection of skin puncture blood from children, with special reference to production of reference values. Scand 7 Clin Lab Invest 1987;47:199-205.

20 Meites S, Hamlin CR, Hayes JR. A study of experimental lancets for blood collection to avoid bone infection of infants. Clin Chem 1992;38:908-10.

21 Nelson DL, Hable KA, Matsen JM. Proteus mirabilis osteomyelitis in two neonates following needle puncture. American fournal of Diseases in Children 1973;125:109-10.

22 Borris LC, Helleland H. Growth disturbance of the hind part of the foot following osteomyelitis of the calcaneus in the newborn. F Bone foint Surg [Am] 1986;68:302-5.

23 Meites S, Lin SS, Thompson C. Studies on the quality of specimens obtained by skin puncture of children. 1 . Tendency to hemolysis, and hemoglobin and tissue fluid as contaminants. Clin Chem 1981;27:875-8. 